\title{
Using the temporal variability of satellite radar altimetric observations to map surface properties of the Antarctic ice sheet
}

\author{
Benoît Legrésy, FrédériQue RÉmy \\ UMR 5566, 18 avenue E. Belin, 31401 Toulouse Cedex 4, France
}

\begin{abstract}
The problem of measuring surface height and snowpack characteristics from satellite radar altimeter echoes is investigated. In this paper, we perform an analysis of the ERS1 altimeter dataset acquired during a 3 day repeat orbit. The analysis reveals that there are temporal variations in shapes of the radar altimeter echo and that these variations are linked to meteorological phenomena. The time- and space-scales over which these variations apply are a few to tens of days and a few hundred kilometres, respectively. This phenomenon, if not accounted for, can create error in the height measurement. A numerical echo model is used to recover snowpack characteristics by taking advantage of the temporal variations of the radar echoes. A map of penetration depth of the radar waves in the Ku band over the Antarctic continent is obtained and suggests that grain-size produces the dominant effect on radar extinction in the snowpack at this frequency. Finally, a procedure is proposed to correct the height measurement within the context of ice-sheet mass-balance survey.
\end{abstract}

\section{INTRODUCTION}

The estimation of ice-sheet volume variations is one of the goals of satellite radar altimetry. However, the major obstacle to the correct interpretation of altimetric data lies in the complex and variable nature of the reflecting snow pack. Indeed, the penetration of radar waves into the snowpack depends on the characteristics of the medium that exhibit both spatial and temporal variability. The lack of knowledge of penetration depth then directly enters into the altimetric height-error budget. Microwave penetration within the snowpack has already been empirically (Ridley and Partington, 1988 ; Davis and Zwally, 1993) and theoretically (Hofer and Mätzler, 1980; Ulaby and others, 1986) estimated for a few specific cases. To our knowledge, this quantity has not been mapped at the continental scale. The same statement applies to the temporal variability of the microwave observations, which has already been pointed out by Ridley and Bamber (1995) and Rott and others (1993a, b).

The aims of this paper are to analyse temporal microwave variations at short time-scales and to map the penetration depth at global scales. The analysis is based on the study of short time-scale ( $\leq 1 \mathrm{month}$ ) variations of the radar-echo parameters (back-scattering, leading-edge width and trailing-edge slope of the altimetric wave form), taking advantage of the ERSl data acquired during phase B. This ERSI phase B was characterized by a $3 \mathrm{~d}$ orbit repeat cycle when the satellite operated in "ocean mode". The corresponding distance between adjacent ground tracks was $380 \mathrm{~km}$ at $66^{\circ}$ latitude and $145 \mathrm{~km}$ at $81^{\circ}$ latitude. Despite the short duration ( 2 months) and poor coverage (large gaps between tracks), the orbit provides a good compromise between spatial and temporal-scale sampling using a single satellite. For
Antarctic coverage, the spatial density of the measurement is good south of $75^{\circ} \mathrm{S}$ and deteriorates throughout the north of the continent.

Such an orbit allows us to assess correctly changes in radar altimetric signal events of duration between 6 days and 1 month with sizes of more than a few tens of kilometres along-track to more than a few hundred kilometres over the Antarctic continent.

The determination of accurate surface topography and geophysical characteristics of the snow pack from altimetric radar wave form is an underdetermined problem for two reasons. First, the topography (height and roughness) is not homogeneous at the radar footprint scale (which is not consistent with Brown's (1977) assumption. This has been discussed by Legrésy and Rémy (1997). The presence of undulations at the footprint scale affects the whole altimetric wave form and makes the inversion of the wave-form data for other geophysical parameters difficult. The second problem is linked to the "volume effect" and has two aspects. The first aspect is the non-linearity of the superposition of volume signal to the deformation of the echo by the surface topography at small scales (e.g. $1-10 \mathrm{~km})$. The second aspect is that the inversion depends on antenna and orbit characteristics which varies from one satellite mission to another.

A fully realistic wave-form model should of course take into account effects described perviously, which would make the inversion problem very complex and certainly computationally prohibitive with respect to simpler conventional models. In any case, because the simultaneous estimation of topographic and snowpack characteristics from waveform inversion is cumbersome, a two-step method can be formulated. The first step would classically consist of esti- 
mating the pertinent parameters describing the altimetric response. These are the back-scattering coefficient $\left(\sigma^{0}\right)$, the width of the leading edge $(T r)$ and the logarithmic slope of the trailing edge $(\mathrm{Fl})$, following Legrésy and Rémy (1997). The second step would then consist of using the altimetric parameters to recover the geophysical characteristics of the snowpack. The main original aspect presented here is that our inversion uses the temporal variations of all the parameters to remove one degree of freedom from the initial "topography + snowpack characteristics" inversion problem.

In the first part of this paper, we shall establish the temporal variations of the radar echo. The observed temporal variations can be caused either by the non-reproducibility of the altimetric measurement or by temporal variability of the snowpack at the surface of ice sheets (Legrésy, 1995). These variations are due to meteorological phenomena affecting the surface micro-roughness. Changes in microroughness affect the ratio between surface and volume signal in the echo and also distort the altimetric wave form. Consequently, there is an artificial variability in the waveform descriptive parameters and in the height measurement. In the second part of this paper, we will take advantage of this variability to add more information to the problem of the altimetric signal inversion and we will then invert a wave-form model.

\section{TEMPORALVARIATIONS OF THE ALTIMETRIC SIGNAL: A ONE-TRACK GASE STUDY}

We have used data from the $223 \mathrm{~d}$ repeat cycles from the ERSl phase $\mathrm{B}$ orbit configuration (January-February 1992). Each cycle contains 43 tracks (see Fig. 1). To derive temporal variability of altimetric parameters, the classical way is to build first a reference mean profile for each parameter and then to look at the anomalies with respect to the mean. This will now be described.

The studied track (Fig. l) is $1050 \mathrm{~km}$ long and includes 3000 individual repeat measurements. In fact, only 13 re-

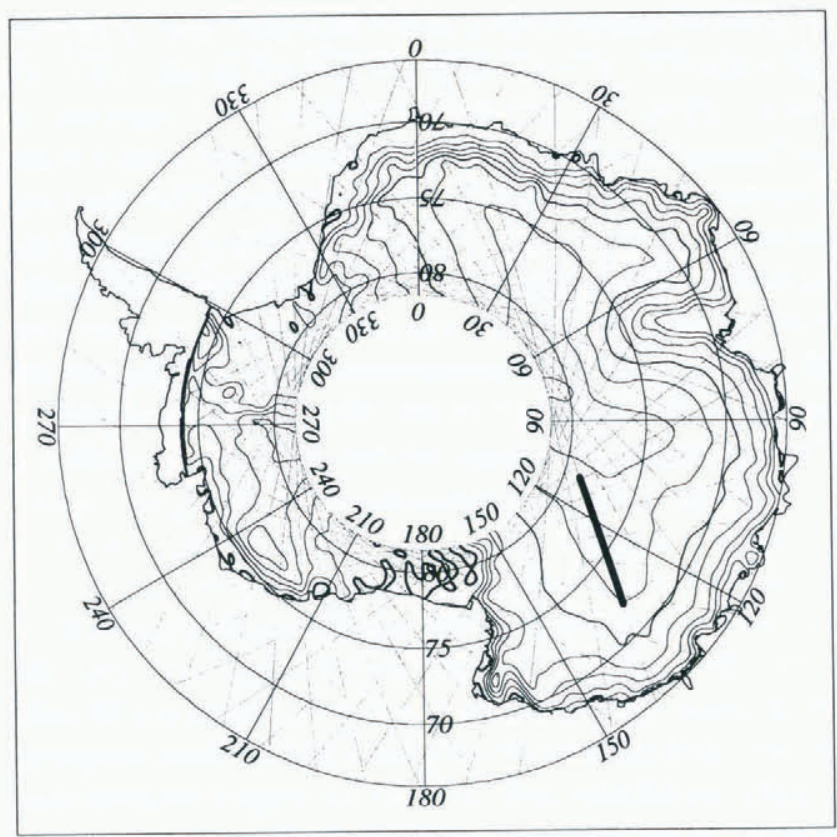

Fig. 1. Map of Antarctica. Contour interval is $100 \mathrm{~m}$. The tracks of the ERS1 3 d repeat cycle are marked as small dots and the $1050 \mathrm{~km}$ track used in this paper is plotted in bold. peat tracks have been used, owing to gaps in the dataset and to erroneous data that have been removed.

\subsection{Description of a mean track}

Figure 2 presents the mean altimetric parameters $\left(H, \sigma^{0}, \mathrm{Tr}\right.$ and $\mathrm{Fl}$ averaged over the 13 repeat measurements) along the track. In the first half of the track $(0-$ $500 \mathrm{~km}$ ), the back-scattering coefficient has low values, while the leading-edge width and the trailing-edge slope have high values. This is the signature of a volume echo (Legrésy and Rémy 1997). In the second half of the track, the presence of a volume echo is not marked. Indeed, the back-scattering coefficient is higher than in the first half of the profile, whereas the leading-edge width and the trailingedge slope have lower values. Notice that this is a first-order approach that should be considered with caution, because of the high noise level on the leading-edge width and the trailing-edge slope parameters. The main difficulty in building the mean profiles is due to non-exact repeatability of the ground track, i.e. the ground-track band width is about $\pm 1 \mathrm{~km}$ with respect to a reference (Rosengren, 1992). In fact, at high latitudes, the shift between the two tracks reaches a maximum of $3 / 100^{\circ}$ in longitude and $3 / 1000^{\circ}$ in latitude.

In this case, one may consider that wave-form parameters are not affected by the geographical displacement if they are smoothed over more than $10 \mathrm{~km}$. (Legrésy and Rémy, 1997). Another source of error in the mean profile interpretation is the slope error. In the case of a $0-2.5 \%$ slope rate (at the scale of the radar footprint) that is observed along the track, the induced error on individual height ranges from 0 to $2.5 \mathrm{~m}$ which is not acceptable. To correct for this error, we computed the across-track topography over a $2 \mathrm{~km}$ band applying a total inversion technique to the ERSl geodetic cycles data as explained in Brisset and Rémy (1996): 743 tracks in the across direction of the $1000 \mathrm{~km}$ observed track were used, leading to a $1.4 \mathrm{~km}$ average distance between each track to be processed through the inversion. The height measurement is then corrected for this displacement by subtracting the geodetic topography precisely interpolated at each point. Finally, the height measurement is also perturbed by orbit errors. The orbit-error spectrum shows dominant peaks at very long wavelengths ( $>$ several tens of thousands of kilometres) (Minster and others, 1992). This orbit error is therefore assumed as only a constant bias on the $1000 \mathrm{~km}$ tracks.

\subsection{Temporal variations along a single track}

The next step in the processing consists of computing the temporal anomalies of the altimetric parameters (Fig. 3) about their mean values. To reduce short-scale noise of the altimetric parameters, the data have been smoothed spatially along the track (using an average sliding window of $10 \mathrm{~km}$ width) and in time (using a 9 day window) because of data gaps either due to lost altimeter tracks or to data editing.

One then finds that the radar back-scattering coefficient shows coherent variations by $\pm 1 \mathrm{~dB}$ at about $15 \mathrm{~d}$ timescales. At the same time, anti-correlated variations occur on the leading edge width $( \pm 0.5 \mathrm{~m}$ or 1 gate). The trailingedge slope does not present a very coherent signal. The significant variations occur particularly on the first half of the track, while the second half does not present the same level of sensitivity. Note that the height parameter, extracted 
(a)

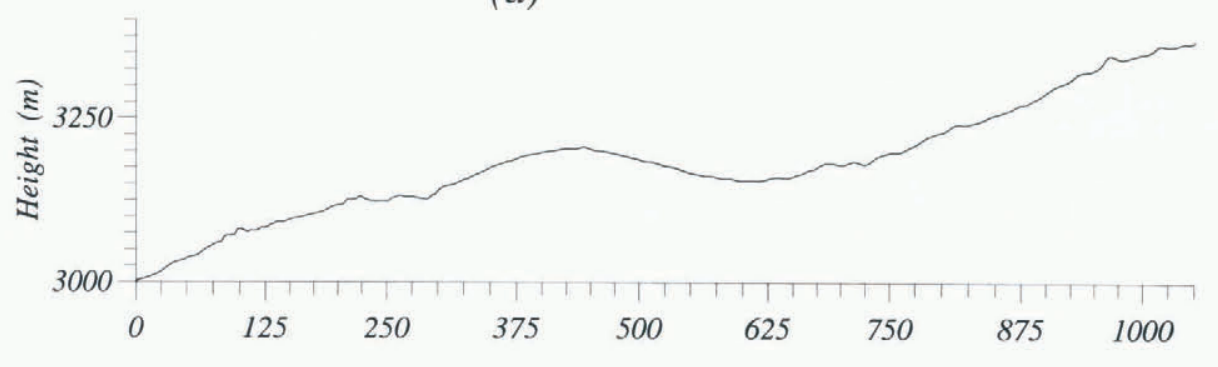

(b)

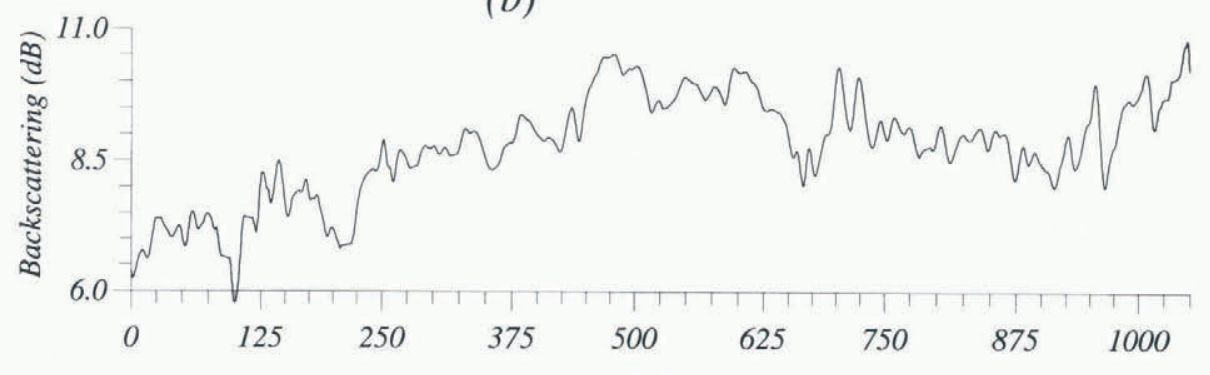

(c)
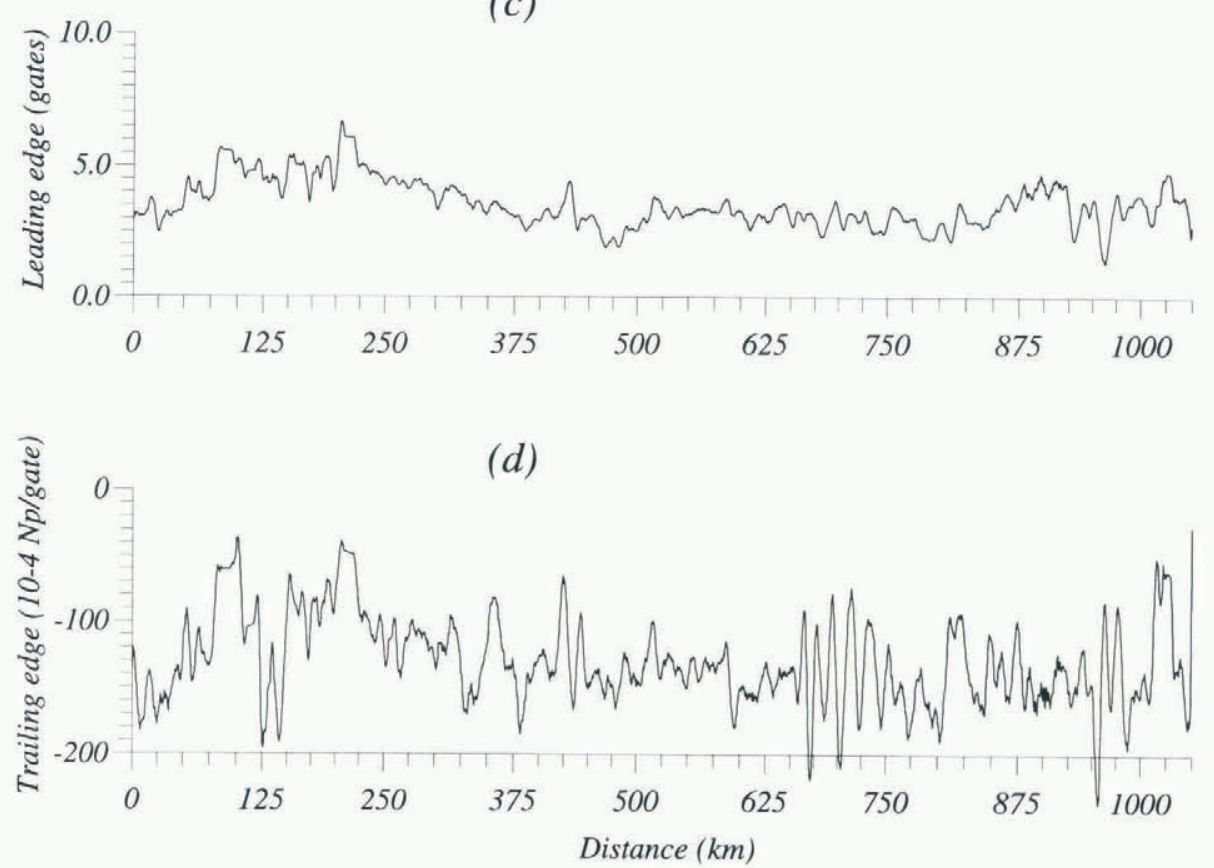

Fig. 2. Mean profiles of the $1050 \mathrm{~km}$ track displayed in Figure 1. The height ( a) ranges from 3000 to $3300 \mathrm{~m}$. The back-scattering coefficient ( $b$ ) varies by $4 \mathrm{~dB}$, being lower at the beginning of the profile. The leading-edge width $(c)$ ranges from 2 to 5 altimetric gates (e.g. $47 \mathrm{~cm}$ equivalent in height), being higher at the beginning of the profile. The trailing-edge slope (d) is highly variable and presents a large-scale decrease of $50 \times 10^{-4} \mathrm{~Np}$ gate ${ }^{-1}$ between the first and second half of the profile.

from the wave-form leading edge is also affected. Figure 4 displays the temporal anomaly of the parameters averaged over the first $500 \mathrm{~km}$ of the track and illustrates the phenomenon. In this figure, the temporal variations averaged over the last $500 \mathrm{~km}$ have been removed (region displaying very low variability). This allows the removal of the orbit bias error on the height and reveals the difference of signal between the beginning and the end of the track.

Figure 4 also shows that there are $70-80 \mathrm{~cm}$ height variations within a short period of time. While this signal is the average of 1400 individual measurements at each date, the confidence in the observed variations is at the $3 \mathrm{~cm}$ level in height. This is, of course, an unrealistic magnitude given the low accumulation in the region and the short time-scales involved. We will now investigate some reasons for this arti- fact. Several possible back-scattering variation mechanisms may be investigated. First, potential causes can lie in the topographic undulations across track (Legrésy and Rémy, 1997). However, the geodetic topography does not present undulations across-track with sufficient amplitudes to modify the back-scattering as observed. A second cause may arise from natural geographical variations in back-scattering in the across-track direction, other than those due to undulations, with amplitudes comparable to the observed $1 \mathrm{~dB}$. Such a reflecting area (for example, a high reflecting but small area) is spread over $\sim 10 \mathrm{~km}$ scales on the altimetric back-scattering (Legrésy and Rémy, 1997) and is thus geometrically impossible here $(50 \mathrm{~dB}$ in amplitude, a few metres wide and $500 \mathrm{~km}$ long is not realistic). Also, neither mispointing nor $\sigma^{0}$ instrumental drift can be invoked because 
(a)

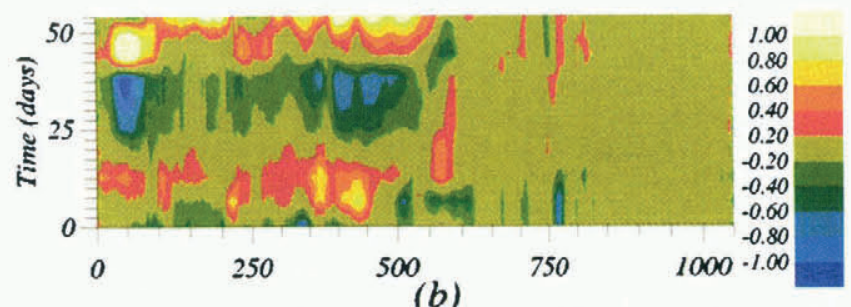

(b)
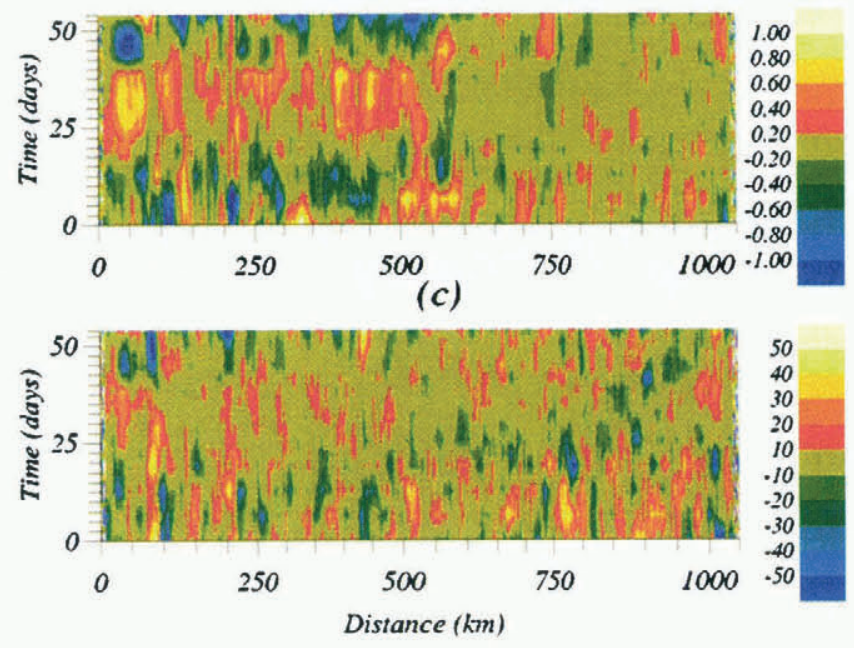

Fig. 3. Temporal anomalies of the wave-form parameters. (a) The back-scattering coefficient (in $\mathrm{dB}$ ), (b) the leadingedge width (in gates), (c) the trailing-edge slope (in $10^{-4}$ $\mathcal{N}$ gate ${ }^{-1}$ ) about the mean shown in Figure 2.

the ERSl platform is stable at $0.01^{\circ}$ and there is no $\sigma^{0}$ drift observed at this time-scale. The last potential cause may arise from the volume-echo contribution to the radar reflection. As already mentioned, the area that exhibits strong temporal variations is affected by volume echo. The observed variations (anti-correlation between $\sigma^{0}$ and
$\mathrm{Tr}, \mathrm{Fl}$ ) suggest a variation of the surface signal. Indeed, a decrease of the surface back-scattering diminishes the total back-scattering and increases the relative weight of the volume part of the signal. As a consequence, the leading edge and the trailing edge are increased. On the other hand, an increase of the surface back-scattering will emphasize the surface characteristics of a wave form which will then display a narrower leading edge and a more sloping trailing edge.

Thus, it is clear that the identified artificial variations in height are highly correlated with variations in back-scattering (and anti-correlated with variations in leading-edge width).

This artifact is limited by "low-retracking" techniques (Bamber, 1994; Legrésy, 1995). These techniques consider the beginning of the leading edge (for example $25 \%$ of the total amplitude). In this case, the observed signal reduces to $50-60 \mathrm{~cm}$ in amplitude, because it is less sensitive to volume echo which acts principally at the end of the wave form. However, the artificial signal is still present at a significant level with respect to the height-accuracy requirements for glaciological measurements, and the interpretation of the measurement becomes biased. This means that any waveform retracking method, not including the volume-echo contribution, may create artificial height variations that should not be interpreted in geophysical terms.

\section{TEMPORAL VARIATIONS OVER THE ANTARC- TIC CONTINENT}

After the analysis of a $1000 \mathrm{~km}$ track case study, it is of interest to extend the study over the whole continent. Even if the spatial coverage is sparse (Fig. 1), it is sufficient to continue a conclusive prospective work. To this end, we computed the data from 22 repeat cycles over the whole continent.

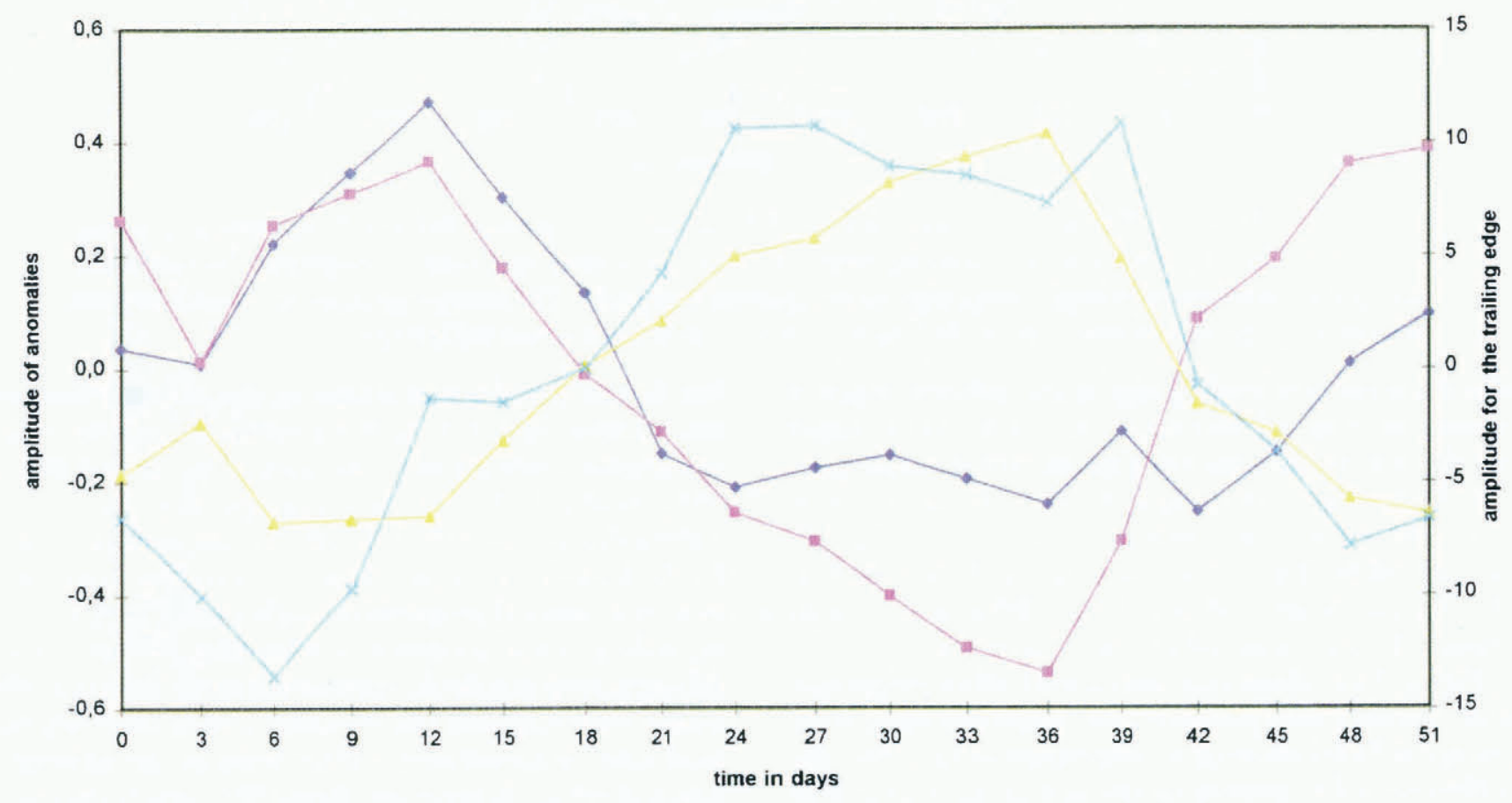

Height $(m)=$ Backscattering $(d B)$ 


\section{1. rms variability}

Mean values of each parameter were computed over a $2^{\circ}$ longitude by $0.5^{\circ}$ latitude grid and mean values are effectively computed in locations where at least 50 data and 11 repeat measurements are available in order to perform significant statistical analyses. Each track is computed independently in order to minimize poor geographical repeatability of the measurements (in the case of multiple tracks within a grid element), and to avoid problems of repeatability between ascending and descending observations (Brisset, 1996). Figure 5 shows maps of the temporal variability in the various parameters in terms of rms. The variability may reach $0.5 \mathrm{~m}$ for the leading edge width, $1 \mathrm{~dB}$ for the back-scattering and 25 units for the trailing-edge slope. The possible variability caused by thermal noise, speckle and retracking is less than $10 \%$ of what is observed here. This variability leads to a "potential variability" of $0.5 \mathrm{~m}$ $\mathrm{rms}$ in the height measurement at 2 months scale. Unlike the retracking error, thermal or speckle noise that are random has spatial correlation over a few hundred kilometres. This error made on the height measurement therefore seems to dominate over other known sources and occurs all over the continent. It is hence necessary to understand well the origin and character of this error.

\subsection{Physical processes of variation}

Variations in the volume part of the signal due to variations in the snow pack temperature, for instance, or to variations in absorption, would not act similarly (an increase in volume part would be associated with an increase both in back-scattering and in leading edge and with a decrease in height). Possible temperature effects will now be examined. The Dome C temperature record (near the single track studied in section l) does not display the same behaviour as the altimetric observation, neither in phase nor in amplitude, even if we take into account the propagation delay within the snowpack. The same conclusion is valid for brightness temperatures derived from the ERSI radiometer and there are no correlations. In fact, during January and February, the evolution of the temperature is dominated by a continuous decrease on which second-order anomalies are superimposed. No similar trend is observed in the altimetric data. Finally, as observed by Brisset (1996), the difference between one summer and one winter $35 \mathrm{~d}$ cycle of ERS1 does not display any major signal, while the temperature difference is $\sim 40 \mathrm{~K}$. Hence, the temperature does not dominate the variations of the volume part of the radar echo observed here.

In addition to analysing the rms variability of the echo parameters, it is also possible to map their temporal anomalies. The observed anomalies are significant and their spatial and temporal characteristics are similar to those of the meteorological perturbation, that is a few hundreds of kilometres and a few to tens of days (Seko and others, 1991). It should be noted that satellite undersampling does not allow adequate observation of meteorological displacement.

The observed correlation allows us to suggest that a realistic mechanism for varying the relative volume contribu-

Fig. 5. Maps of the rms variability of the various parameters over the Antarctic ice sheet. (a) The back-scattering coefficient (in $d B$ ), (b) the leading-edge width (in gates), (c) the trailing-edge slope (in $10^{-4} \mathrm{~Np}$ gate ${ }^{-1}$ ).
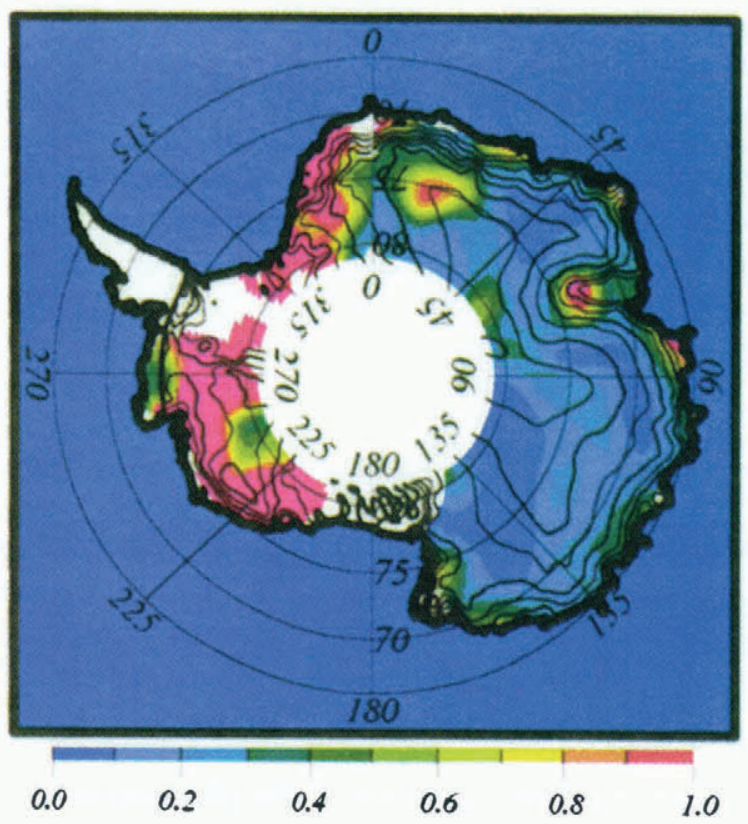

(a): R.M.S. Backscattering (dB)

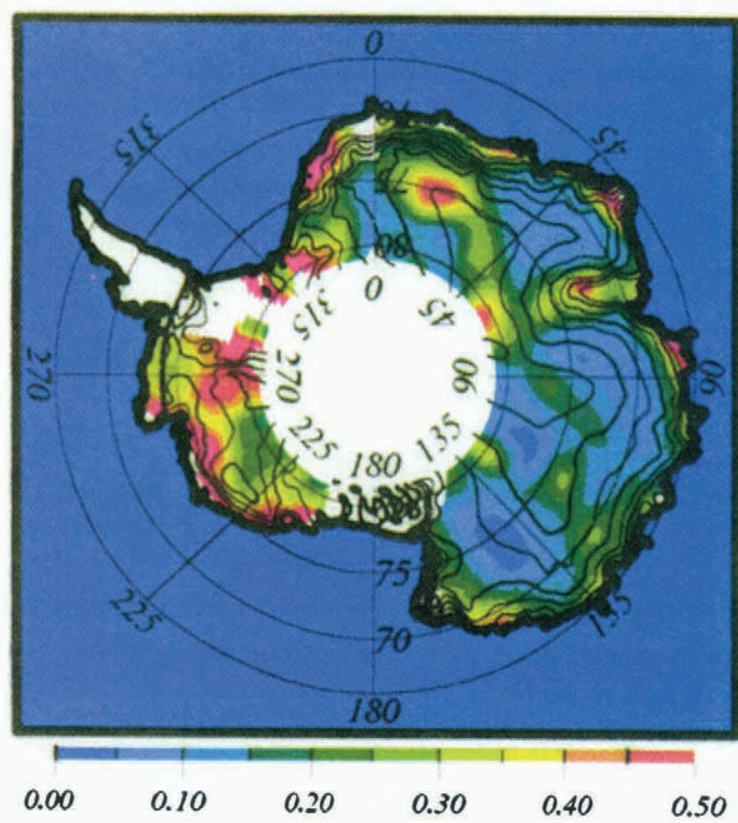

(b): R.M.S. Leading edge (gates)

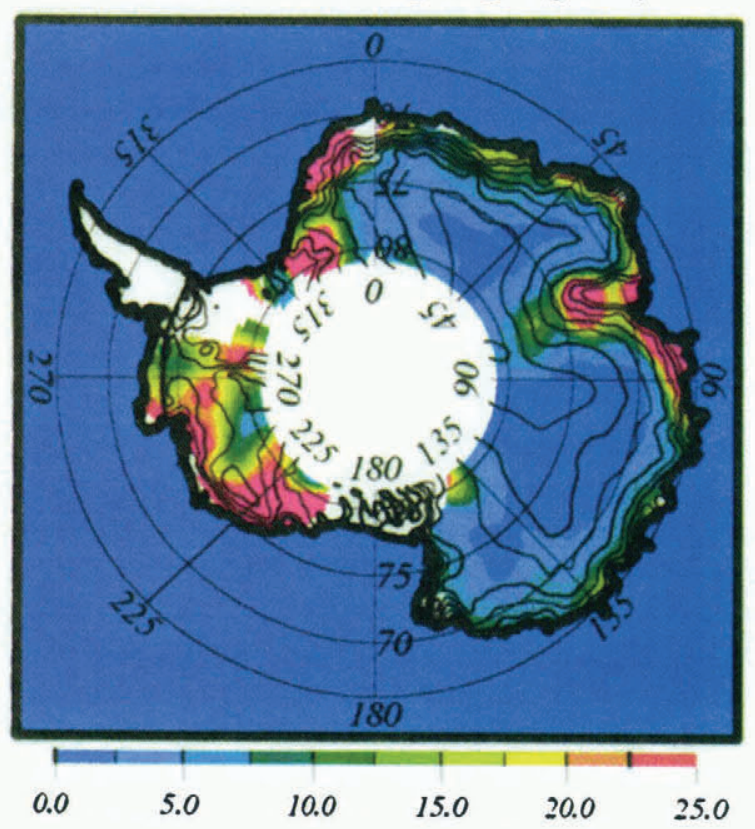

(c): R.M.S. Trailing edge (10-4 Np/gate) 
tion to the altimetric echo is that meteorological events change the wind pattern and thus the surface micro-roughness. Because surface back-scattering is very sensitive to surface micro-roughness (Rémy and others, 1990), this may create fluctuations in surface back-scattering. The wind effect is complex. Kobayashi (1979) reported modification of the surface micro-roughness induced by cyclonic wind above the katabatic wind-formed patterns. However, we do not have sufficient elements to make more precise conclusions about the wind processes. Another possibility is that the hoar-frost growth and grain recrystallization, controlled by the rate of temperature change, alter the relative proportion of surface and sub-surface signals.. This possibility must be considered with care. The observed phenomena have to be reversible. The observed temperature record at Dome $\mathrm{C}$ does not show rates of temperature change correlated with the back-scatter changes. The better candidate for creating this signal remains wind processes.

\subsection{Geographical signature of the phenomena}

Although the large-scale variations show a common pattern for the three wave-form parameters, the effect of variation in back-scattering on both wave-form shape parameters produces a geographical signal. The high variations of back-scattering in West Antarctica at longitude $270^{\circ}$ or $225^{\circ} \mathrm{E}$ induce high responses in leading-edge width at $270^{\circ} \mathrm{E}$. The same effect is less impressive at longitude $225^{\circ} \mathrm{E}$. This geographical behaviour of wave-form shape with respect to change in back-scattering is shown in Figure 6. Both maps show a coherent signal and are decorrelated with each other. While the leading edge is very sensitive to changes in $\sigma^{0}$ near Tallos dome $\left(155^{\circ} \mathrm{E}\right)$, the trailing edge shows less sensitivity. Conversely, near $135^{\circ} \mathrm{E}$ and $80^{\circ} \mathrm{S}$, the leading edge is not very sensitive while the trailing edge is more sensitive. It is clear that this sensitivity is related to snowpack characteristics. These characteristics could therefore be deduced from an analysis of both maps using a waveform model to perform an inversion.

\section{INVERSION OF THE SIGNAL}

\subsection{Methodology}

The retrieval of penetration-depth and volume-echo contributions to back-scattering will be performed following a two-step methodology. The first step will consist of establishing a theoretical model of leading-edge width and trailing-edge slope variations with respect to surface backscattering changes by considering the volume-echo contribution to back-scattering. The second step will use the derived model to invert ERSl data, as shown in Figure 6, to recover penetration-depth and volume-echo contributions to back-scattering over Antarctica.

The numerical echo model as developed in Legrésy and Rémy (1997) is used. This echo model allows us to simulate wave forms from a finely digitized topography in order to have as realistic wave forms as possible, taking into account satellite characteristics (e.g. altitude and antenna patterns) and surface back-scattering $\left(\sigma_{\mathrm{s}}\right)$. Volume echo is included in the simulation using a simple model controlled by the contribution of a "one-gate equivalent layer" to back-scattering $\left(\sigma_{\mathrm{v}}\right)$, resulting from stratification and ice-grain scattering, and by the extinction through the snowpack $\left(x_{\mathrm{e}}\right)$ - or

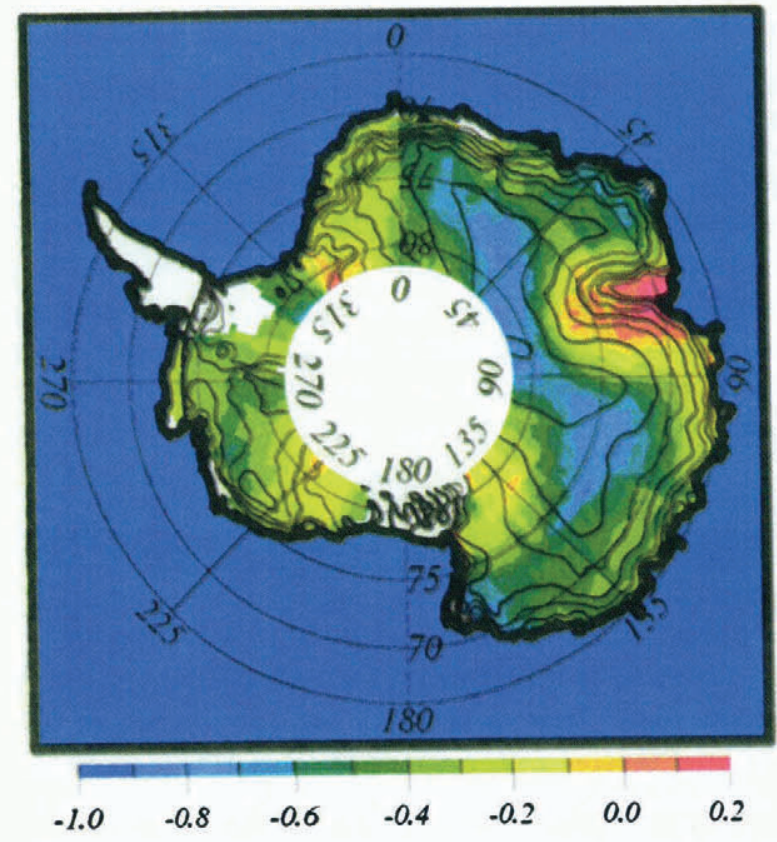

(a) : $d T r / d s i g m a 0$

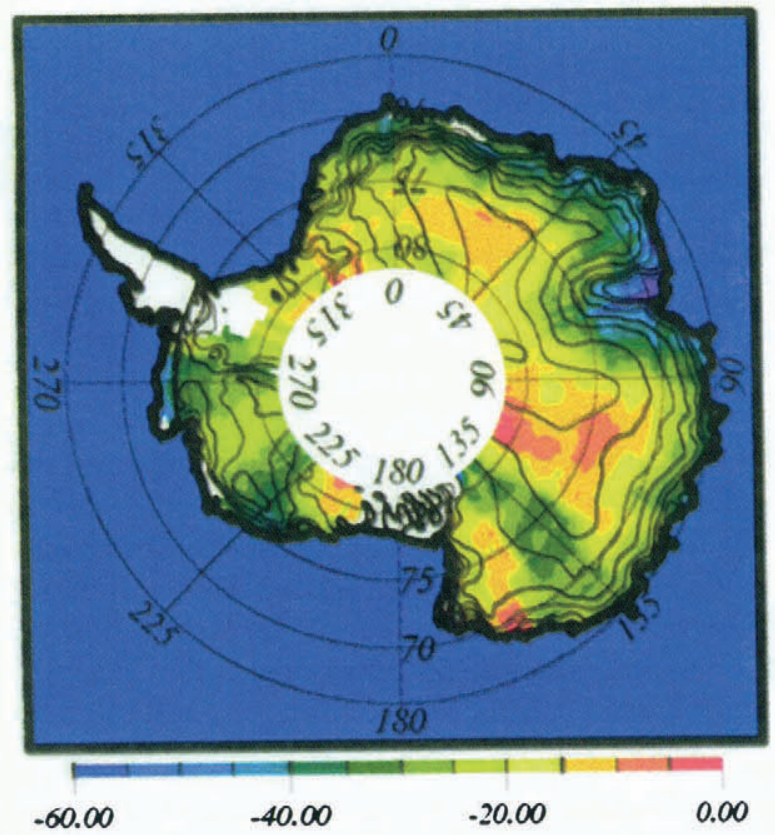

(b) : dFV dSigmaO

Fig. 6. Maps of the regression between (a) the back-scattering coefficient and the leading-edge width temporal variations (in gates $d B^{-1}$ ), (b) the back-scattering coefficient and the trailing-edge slope temporal variations (in $10^{-4} \mathrm{~Np}$ gate $^{-1}$ $d B^{-1}$.

equivalently the penetration depth $\left(d_{\mathrm{p}}\right)$ - resulting from absorption and ice-grain scattering. The output of this model includes wave forms, which are retracked in the same manner as data analysed in the previous sections. All the wave-form parameters are then recovered: $\sigma^{0}$, leading-edge width and trailing-edge slope.

\subsection{Modeling variations of wave-form parameters}

Theoretical values of $\mathrm{d} T r / \mathrm{d} \sigma^{0}$ and $\mathrm{d} F l / \mathrm{d} \sigma^{0}$ are computed by varying $\sigma_{\mathrm{s}}$ between 0.5 and 1.5 times the reference value $\left(\sigma_{\text {ref }}\right)$, and by keeping the volume echo constant with respect to this reference value. The variable $\sigma_{\text {ref }}$ is the surface backscattering corresponding to the roughness configuration 
present from the internal layers. Fifty real topographic situations with roughness and sub-footprint topography have been averaged for each configuration $\left(\sigma_{\mathrm{s}}, \sigma_{\mathrm{v}}, x_{\mathrm{e}}\right)$; this makes the result more relevant to the mapped data. When $\sigma_{\mathrm{s}}$

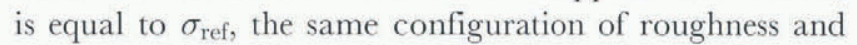
micro-roughness is considered at the surface and at the internal interfaces. The relations $\operatorname{Tr}\left(\sigma^{0}\right)$ and $F l\left(\sigma^{0}\right)$ are verified as being linear. The parameters are then processed for 50 different real topographic patterns and for couples $\left(\sigma_{\mathrm{v}} / \sigma_{\text {ref }} ; d_{\mathrm{p}}\right)$ ranging as $(0-0.5 ; 0-20 \mathrm{~m})$. The resulting diagrams are shown in Figure 7 where the total volume part increases from the lower lefthand corner (no penetration and no volume scattering) up to the upper righthand corner (strong penetration and strong volume scattering). Both the trailing-edge slope and leading-edge width decrease (negative derivatives) while surface scattering increases. Surfacescattering fluctuations greatly affect the trailing-edge slope when the volume part is important but have less effect when the volume part is weak. Surface-scattering fluctuations have a strong effect on the leading-edge width. The fluctuations of both leading edge and trailing edge due to change in surface back-scattering exhibit a different behaviour with respect to volume-signal characteristics. This difference allows inversion of Figure $6 \mathrm{a}$ and $\mathrm{b}$ and the recovery of both volume-scattering and penetration depth.

\subsection{Volume-scattering and penetration depth over Antarctica}

A linear inverse process, using a classical least-squares minimization technique, produces the first global maps of $\sigma_{\mathrm{v}} / \sigma_{\text {ref }}$ and $d_{\mathrm{p}}$ (Fig. 8). Offsets between observed ERSl data and the model are weighted by the standard deviation of the parameters in the dataset.

The penetration-depth values vary from $7 \mathrm{~m}$ within the continent to $13 \mathrm{~m}$ at a lower altitude. These values are in good agreement with some of the previous estimates. Ulaby and others (1986) listed penetration depths of about $10 \mathrm{~m}$ at $13 \mathrm{GHz}$ into dry snow, with an $0.24 \mathrm{Mg} \mathrm{m}^{-3}$ density and an $0.5 \mathrm{~mm}$ ice grain-size, while Hofer and Mätzler (1980) predicted penetration depths of $7 \mathrm{~m}$ at $13 \mathrm{GHz}$. With the help of Seasat altimeter wave-form analysis, Ridley and Partington (1988) found a penetration depth of $8 \mathrm{~m}$ in a small area. Using Geosat altimeter data, Davis and Zwally (1993) found penetration depths varying from 5 to $10 \mathrm{~m}$ in a small area, north of $72^{\circ} \mathrm{S}$ in Wilkes Land. Both studies relied on waveform analysis but were not performed on a global scale. These estimates are limited by the wave-form averaging procedure and by limitation to flat regions. The error of penetration-depth estimation associated with the present method has been evaluated by two means: first, the error in regression calculation inferred by noise has been calculated. The correlation between this error of inputs and output is $2.7 \times 10^{-2}$, indicating that there is no relation between this error on the inputs and the output of the inversion. Secondly, the initial values have been perturbed by a Monte-Carlo method. The map of the maximum error given by the Monte-Carlo method on the penetration depth (not displayed here) presents an homogeneous signal of the order of $3 \mathrm{~m}$ that can be associated with the inversion. Although the order of magnitude of the extinction calculated here is in accordance with the previous values, the results should be discussed as there are disagreements in the spatial distribution and interpretation.
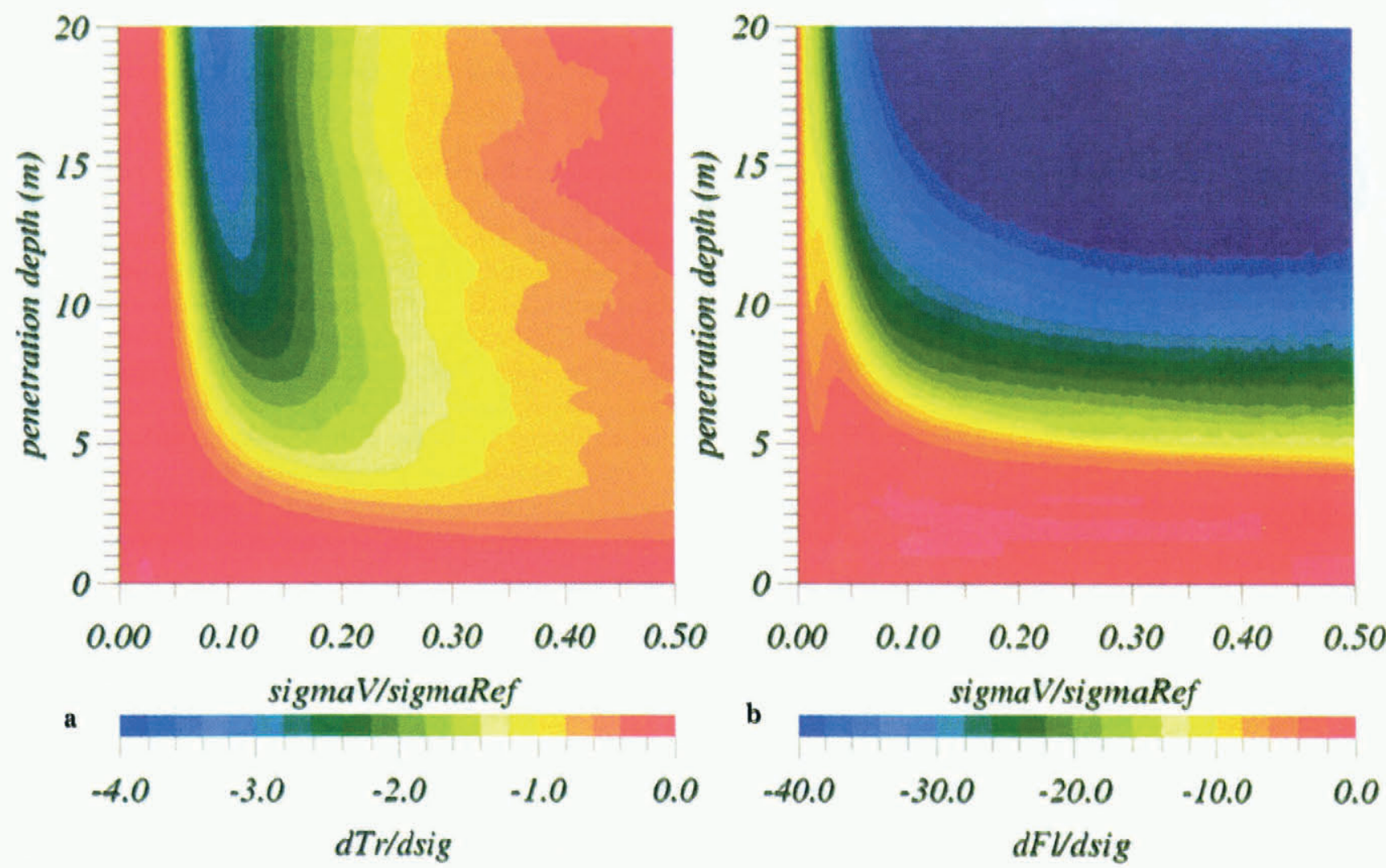

Fig. 7. Theoretical regressions: (a) the back-scattering coefficient and the leading-edge width (in gates d $B^{-1}$ ), (b) the backscattering coefficient and the trailing-edge slope (in $10^{-4} \mathrm{~Np} \mathrm{gate}^{-1} \mathrm{dB^{-1 }}$ ) obtained by varying the surface back-scattering for each of the volume-echo configurations. 


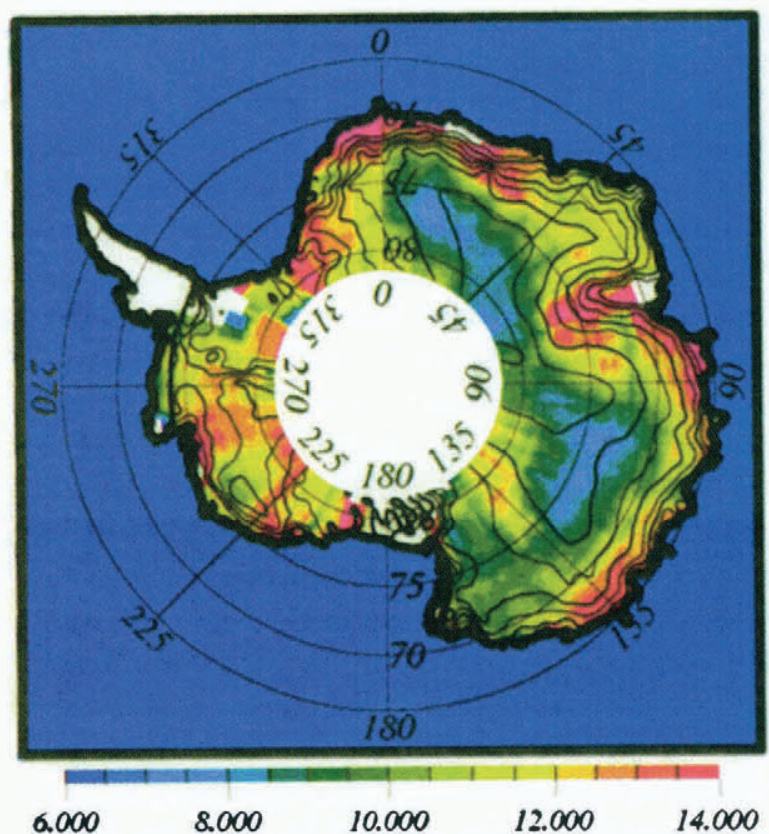

(a) : penetration depth $(m)$
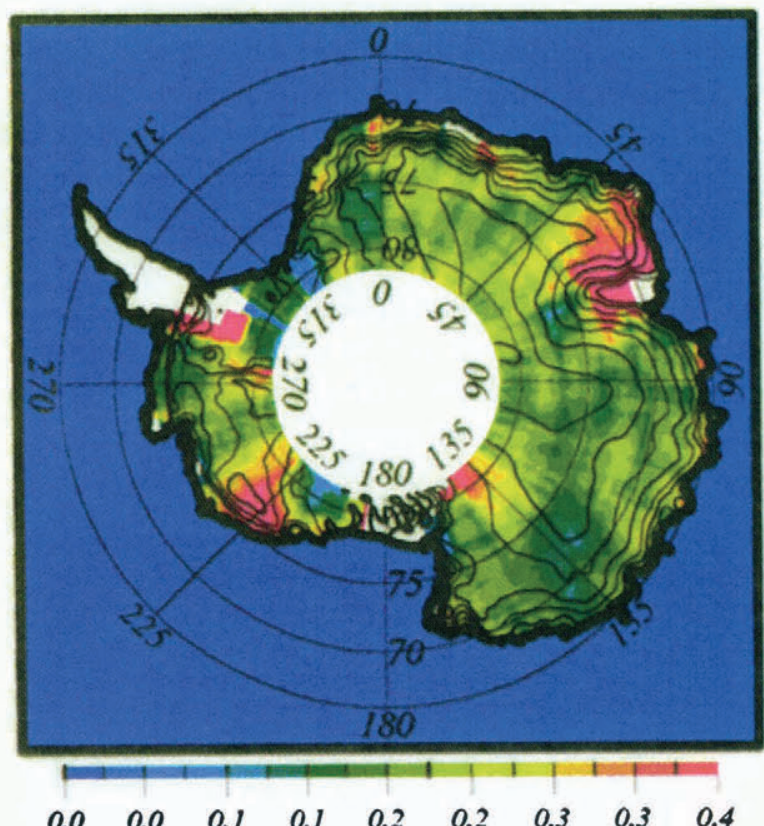

(b) : sigmav/sigmaref

Fig. 8. Maps of (a) the penetration depth ( $m$ ) of Ku radar waves inside the snowpack; (b) the volume contribution (back-scattering of one $\sim 30 \mathrm{~cm}$ layer/mean surface backscattering).

\section{DISCUSSION}

\subsection{Penetration depth and ice grain-size}

The extinction coefficient is due to losses by absorption and scattering $\left(k_{\mathrm{e}}=k_{\mathrm{a}}+k_{\mathrm{s}}\right.$ ). Absorption is mostly controlled by the temperature (Mätzler, 1987) and decreases from the coast to the dome. According to Mätzler (1987), the uncertainty about the actual behaviour of the imaginary part of the dielectric constant of dry snow with respect to temperature is serious and limits the interpretation of the microwave signature. In any case, as the temperature decreases from the coast to the interior of the continent, the absorption should behave similarly.

Scattering is mostly controlled by grain-size. Gow (1969) discussed the depth-time-temperature relationships of icecrystal growth. The behaviour with depth of crystal growth can be expressed as

$$
D^{2}-D_{0}^{2}=k_{0} \exp ^{(-E / R T)} z / a c c
$$

where $D$ and $D_{0}$ are the equivalent size of the crystal at a depth $z$ and at the surface, respectively, $E$ is the activation energy (of the order of $45 \mathrm{~J}^{\text {mole }}{ }^{-1}$ ), $R$ is the gas constant, $k_{0}$ is a constant, acc the accumulation rate and $T$ is the temperature of the snowpack. It is the grain-size in the first few metres of firn that plays a significant role on the radar observation. Hence, there are two principal physical phenomena which have opposite effects. Higher temperatures cause the snow grains to grow quickly, whereas higher accumulation rates cause them to grow slowly. There are many other physical phenomena acting on the grain-size. For example, the wind may crush the snow grains (Colbeck, 1980) and create smaller grains in low-accumulation regions. Using groundtraverse data from Mirny $\left(66^{\circ} 33^{\prime} \mathrm{S}, 93^{\circ} 01^{\prime} \mathrm{E}\right)$ to Vostok $\left(78^{\circ} 28^{\prime} \mathrm{S}, 106^{\circ} 49^{\prime} \mathrm{E}\right)$, Surdyk and Fily (1993) showed that the grain-size increases from the coast to the dome. At such a scale, it can therefore be concluded that the accumulation rate is the dominant controlling factor of grain-size (and a fortiori the scattering coefficient), with a lower effect from temperature. The large-scale behaviour shown in Figure 8 suggests that geographical variations of the extinction coefficient are predominantly controlled by grain-size.

Following Comiso and others (1982), a constant absorption coefficient of $0.04 \mathrm{~m}^{-1}$ is assumed. The penetrationdepth distribution gives a scattering coefficient varying from 0.03 to $0.16 \mathrm{~m}^{-1}$. Assuming a cubic dependence law between scattering coefficient and grain-size (Zwally, 1977), the equivalent diameter of snow grains is found to vary from $0.6 \mathrm{~mm}$ in the plateau region to $0.34 \mathrm{~mm}$ at lower altitudes. In comparison, Surdyk and Fily (1993) reported grain-sizes ranging from 0.2 to $3 \mathrm{~mm}$ using a large dataset of observed values. In addition, they pointed out that the gradient ratio of brightness temperatures between two frequencies is linked to snow grain-size. The gradient-ratio map is obtained (see Fig. 9) from the ERS1 radiometer data which give brightness temperatures at the vertical incidence of 23.8 and $36.5 \mathrm{GHz}$. The lower the ratio, the greater the grain-size and, consequently, the greater the scattering and the lower the penetration depth. This map is consistent with the penetration-depth map in East Antarctica. This confirms that the extinction is mostly controlled by scattering through grain-size. However, this has not been verified in West Antarctica, where the higher temperature perturbs the gradient-ratio significance (Surdyk and Fily, 1993). In fact, higher temperature implies a higher temperature gradient in the snowpack that influences the gradient-ratio measurement.

Finally, the large-scale signal of the penetration depth of radar waves (in the $\mathrm{Ku}$ band) within the snowpack seems to be more controlled by accumulation rate than by temperature, as was assumed by Davis and Zwally (1993).

\subsection{Volume contribution}

The volume-contribution (back-scattering of one $\sim 30 \mathrm{~cm}$ layer/mean surface back-scattering) map displays values from 0.05 to 0.4 . The volume signal may be due to scattering by ice grains (Ridley and Partington, 1988), yet internal stratification is found empirically to be the dominant effect 

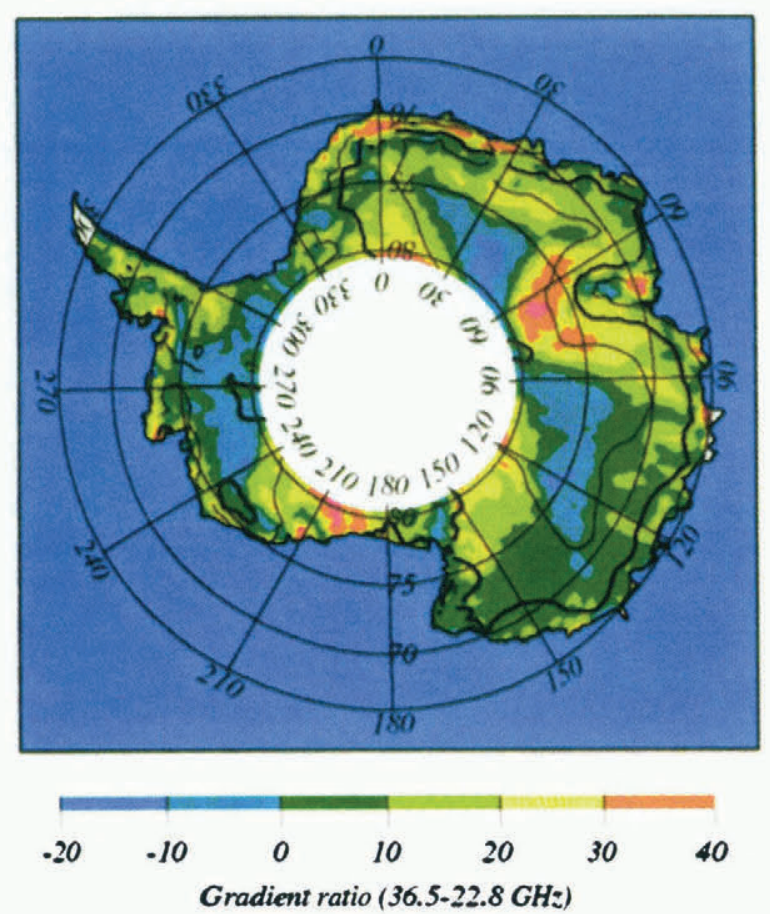

Fig. 9. Map of the "gradient ratio" (in 1/1000) of brightness temperatures at 23.8 and $36.5 \mathrm{GHz}$ obtained with the ERS1 radiometer. This ratio is empirically found to be linked to the snow grain-size by Surdyk and Fily (1993).

acting on the altimetric wave forms (Rémy and others, 1995). In this case, volume contribution depends both on the internal stratification intensity and on the number of strata. The number of strata per depth unit is important when the accumulation rate is low. The weak stratificaiton found in Wilkes Land (Goodwin, 1988) is due to the high accumulation rate in this region (Bromwich, 1988), while the higher stratification near domes is due to the low accumulation rate (Surdyk and Fily, 1993).

Internal stratification intensity is representative of the density contrast from one layer to another and shows considerable variations from one region to another. Various phenomena play a role in the firn stratification such as snowdrift (Takahashi and others, 1988) or wind crusts (Goodwin, 1991).

Rott and others (1992a, b) reported internal density variations of 0.1 and $0.05 \mathrm{~g} \mathrm{~cm}^{-2} \mathrm{rms}$, respectively, each $5 \mathrm{~cm}$ in East Antarctica for two sites less than $100 \mathrm{~km}$ apart, showing the spatial variability of the stratification. The geographical signal of volume contribution, in general, does not show any coherent pattern, except in some areas. The fact that snowpack characteristics depend on various climatic processes such as accumulation, temperature variations and snowdrifting may explain the poor geographical signature of this parameter.

\subsection{Long-term ice-sheet volume survey}

The strong temporal variability exhibited here has an important consequence on ice-sheet volume surveyed from temporal altimetric series. First, the short-scale signal must be corrected. It is possible to do this using the wave-form model, the snowpack characteristics and the measured leading-edge width. Figure 10 shows the error on the height measurement as derived here, for a mean 2.3 gates "surface" leading-edge width. Assuming a residual error of $10 \%$, this yields a raw noise estimate of $10 \mathrm{~cm}$. For a minimal required precision of $2 \mathrm{~cm}_{\text {year }}{ }^{-1}$, and for good sampling of seasonal

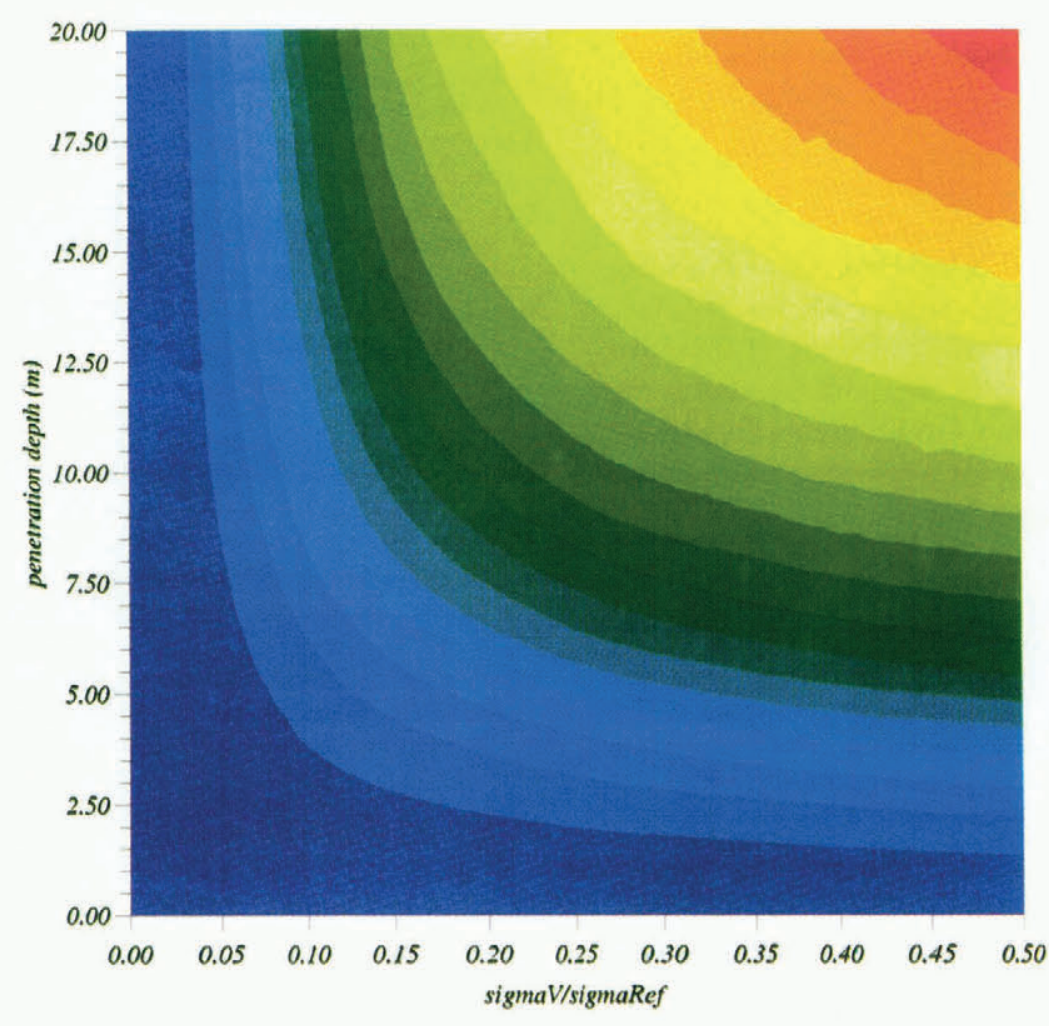

$\begin{array}{lllllllllll}0.0 & 0.2 & 0.4 & 0.6 & 0.8 & 1.0 & 1.2 & 1.4 & 1.6 & 1.8 & 2.0 \\ & & & & d H / d \text { sigma }(\mathrm{m} / \mathrm{dB})\end{array}$

Fig. 10. Diagram of the height-variation artifact induced by surface-scattering variations in the presence of volume echo $\left(\right.$ in $\left.m d B^{-1}\right)$. 
effects, about 25 measurements per year are required, leading to a short repeatability of around $15 \mathrm{~d}$, which is of the order of oceanic requirements. The future missions, being planned to have a larger repetition time, will make this problem critical. Secondly, climatic change will probably produce long-term changes both in the accumulation rate and wind regime. These changes probably also have a seasonal signature as suggested by Van der Veen and Jezek (1993). The challenge will be to discriminate between real changes in ice volume and observation noise. The climatic survey of ice sheets must then be done with the help of time series of both altimetric height and altimetric parameters (e.g. backscattering, leading-edge width and trailing-edge slope).

\section{CONCLUSION}

We have presented here some important variations in the altimetric wave-form shape at short time-scales (a few days). There is strong circumstantial evidence that these variations are associated with meteorological events and that they create an artifact on the height measurement. These variations allows us to estimate snowpack characteristics, such as the penetration depth and volume back-scattering contribution from an inversion of a radar-echo model. The resulting map of penetration depth shows a strong coherent signal. The extinction of radar waves within the snowpack is found to be mostly linked with snow grainsize and temperature is a second-order effect. The survey of ice-sheet volume is therefore perturbed by this artifact. Given the rms variability measured on the 2 months long record (Fig. 5), the snowpack characteristics (deduced in Fig. 8) and the impact on height (Fig. 10), the resulting error that can be potentially reduced lies within $1 \mathrm{~m}$ in the western part of the ice sheet and more frequently around $40 \mathrm{~cm}$ in the eastern part. The survey of the altimetric wave-form shape will allow estimation of both ice-sheet mass balance and ice-sheet surface climate.

\section{ACKNOWLEDGEMENTS}

We thank P. Vincent from CNES for rigorously reviewing the paper and for constructive discussion. M. Fily (LGGE, Grenoble) is thanked for his useful comments. L. Eymard (CETP, Paris) is thanked for providing ERS radiometric data. B. Legrésy was funded by a CNES grant. Finally, we also thank J. Gunson (GRGS) for reviewing the English version of the paper.

\section{REFERENCES}

Bamber, J. L. 1994. Ice sheet altimeter processing scheme. Int. F. Remote Sensing, 15 (4), 925-938.

Brisset, L. 1996. La calotte Est Antarctique observée par ERS-l: aspects stationnaire et dynamique. (Thèse de doctorat, Université Paris VII.)

Brisset, L. and F. Rémy. 1996. Antarctic topography and kilometre-scale roughness derived from ERS-1 altimetry. Ann. Glaciol., 23, 374-381.

Bromwich, D. H. 1988. Snowfall in high southern latitudes. Rev. Geophys., 26(1), 149-168.

Brown, G. S. 1977. The average impulse response of a rough surface and its application. IEEE Trans. Antennas Propag., AP-25 (1), 67-73.

Colbeck, S. C. 1980. Dynamics of snow and ice masses. New York, etc., Academic Press.

Comiso, J. C., H. J. Zwally and J. L. Saba. 1982. Radiative transfer modeling of microwave emission and dependence on firn properties. Ann. Glaciol., $3,54-58$.

Davis, C. H. and H.J. Zwally. 1993. Geographic and seasonal variations in the surface properties of the ice sheets by satellite-radar altimetry. $\mathcal{F}$. Glaciol., 39 (133), 687-697.

Goodwin, I. D. 1988. Firn core data from shallow drilling investigations in eastern Wilkes Land, East Antarctica. A.NARE Res, Notes 65.

Goodwin, I. D. 1991. Snow-accumulation variability from seasonal surface observations and firn-core stratigraphy, eastern Wilkes Land, Antarctica. J. Glaciol., 37 (127), 383-387.

Gow, A. J. 1969. On the rates of growth of grains and crystals in South Polar firn. F. Glaciol., 8(53), 241-252.

Hofer, R. and C. Mätzler. 1980. Investigations on snow parameters by radiometry in the 3- to $60-\mathrm{mm}$ wavelength region. f. Geophys. Res., $85(\mathrm{Cl}), 453-460$.

Kobayashi, S. 1979. Studies on interaction between wind and dry snow surface. Contrib. Inst. Low Temp. Sci., Ser. A 29.

Legrésy, B. 1995. Étude du retracking des formes d'onde altimétriques au-dessus des calottes polaires. ESA Contract Rep. 856/2/95/CNES/006, CNES Report CT/ED TU/UD/96.188.

Legrésy, B. and F. Rémy. 1997. Altimetric observations of surface characteristics of the Antarctic ice sheet. F. Glaciol., 43(144), 265-275; Erratum $43(145), 595-596$.

Mätzler, C. 1987. Applications of the interaction of microwaves with the natural snow cover. Remote Sensing Rev., 2 (2), 259-387.

Minster, J. F., C. Brossier, M. C. Gennero, S. Houry and P. Vincent. 1993. Space and time variability of the Gulf Stream using ERSI ALTOPR02 data. In Kaldeich, B., ed. Proceedings of the First ERS-1 Symposium Space at the Service of our Environment, 4-6 November 1992, Cannes, France. Vol. 1. Paris, European Space Agency, 419-423. (ESA Special Publication SP359.)

Rémy, F., C. Brossier and J. F. Minster. 1990. Intensity of satellite radar-altimeter return power over continental ice: a potential measurement of katabatic wind intensity. 7. Glaciol., 36(123), 133-142.

Rémy, F., P. Féménias, M. Ledroit and J. F. Minster. 1995. Empirical microwave backscattering over Antarctica: application to radar altimetry: $\vec{f}$. Electromagn. Waves Appl., 9 (3), 463-474.

Ridley, J. K. and J. L. Bamber. 1995. Antarctic field measurements of radar backscatter from snow and comparison with ERS-1 altimeter data. $\mathcal{F}$. Electromagn. Waves Appl., 9 (3), 355-371.

Ridley, J. K. and K. C. Partington. 1988. A model of satellite radar altimeter return from ice sheets. Int. f. Remote Sensing, 9 (4), 601-624.

Rosengren, M. 1992. ERSl and Earth observer that exactly follows its chosen path. ESA Bulletin 72, $76-82$.

Rott, H., K. Sturm and H. Miller. 1993a. Active and passive microwave signatures of Antarctic firn by means of field measurements and satellite data. Ann. Glaciol., 17, 337-343.

Rott, H., K. Sturm and H. Miller. 1993b. Signatures of Antarctic firn by means of ERS-1 AMI and by field measurements. In Kaldeich, B., ed. Proceedings of the First ERS-1 Symposium Space at the Service of our Environment, 4-6 November 1992, Cannes, France. Vol. 1. Paris, European Space Agency, 227-233. (ESA Special Publication SP-359.)

Seko, S., M. Wada and S. Aoki. 1991. The characteristic variation of Tb in the Antarctic region revealed by NOAA AVHRR channel-4 data. Proc. NIPR Symp. Polar Meteorol. Glaciol. 4, 31-42.

Surdyk, S. and M. Fily. 1993. Comparison of the passive microwave spectral signature of the Antarctic ice sheet with ground traverse data. Ann. Glaciol., 17, 161-166.

Takahashi, S., R. Naruse, M. Nakawo and S. Mae. 1988. A bare ice field in east Queen Maud Land, Antarctica, caused by horizontal divergence of drifting snow. Ann. Glaciol., 11, 156-160.

Ulaby, F. T., R. K. Moore and A. K. Fung. 1986. Microwave remote sensing, active and passive. Vol. 3. Reading, MA, Addison-Wesley Publishing Co.

Van der Veen, C. J. and K. C. Jezek. 1993. Seasonal variations in brightness temperature for central Antarctica. Ann. Glaciol., 17,300-306.

Zwally, H.J. 1977. Microwave emissivity and accumulation rate of polar firn. f. Glaciol., 18 (79), 195-215. 